\title{
Postnatal Switch from Synaptic to Extrasynaptic Transmission between Interneurons and NG2 Cells
}

\author{
Mateo Vélez-Fort, ${ }^{1,2,3}$ Paloma P. Maldonado, ${ }^{1,2,3}$ Arthur M. Butt, ${ }^{4}$ Etienne Audinat,,${ }^{1,2,3}$ and María Cecilia Angulo ${ }^{1,2,3}$ \\ ${ }^{1}$ Institut National de la Santé et de la Recherche Médicale Unité 603, ${ }^{2}$ Centre National de la Recherche Scientifique Unité Mixte de Recherche 8154, \\ ${ }^{3}$ Université Paris Descartes, 75006 Paris, France, and ${ }^{4}$ Institute for Biomedical and Biomolecular Sciences, School of Pharmacy and Biomedical Sciences, \\ University of Portsmouth, Portsmouth 201 UP, United Kingdom
}

NG2 cells, oligodendrocyte precursors, play a critical role in myelination during postnatal brain maturation, but a pool of these precursors is maintained in the adult and recruited to lesions in demyelinating diseases. NG2 cells in immature animals have recently been shown to receive synaptic inputs from neurons, and these have been assumed to persist in the adult. Here, we investigated the GABAergic synaptic activity of NG2 cells in acute slices of the barrel cortex of NG2-DsRed transgenic mice during the first postnatal month, which corresponds to the period of active myelination in the neocortex. Our data demonstrated that the frequency of spontaneous and miniature GABAergic synaptic activity of cortical NG2 cells dramatically decreases after the second postnatal week, indicating a decrease in the number of synaptic inputs onto NG2 cells during development. However, NG2 cells still receive GABAergic inputs from interneurons in the adult cortex. These inputs do not rely on the presence of functional synapses but involve a form of GABA spillover. This GABA volume transmission allows interneurons to induce phasic responses in target $\mathrm{NG}_{2}$ cells through the activation of extrasynaptic $\mathrm{GABA}_{\mathrm{A}}$ receptors. Hence, after development is complete, volume transmission allows NG2 cells to integrate neuronal activity patterns at frequencies occurring during in vivo sensory stimulation.

\section{Introduction}

Oligodendrocyte precursors expressing the proteoglycan NG2 (NG2 cells) constitute a main type of glial cell in the postnatal (PN) brain (Nishiyama et al., 2009). These cells represent an important endogenous pool of progenitors for oligodendrocytes in the adult, although they are also regarded as multipotent cells endowed with the ability to generate presumably astrocytes and neurons (Guo et al., 2009; Nishiyama et al., 2009). In pathological conditions, NG2 cells serve as a major source of remyelinating oligodendrocytes in demyelinated lesions (Chang et al., 2000). Anatomical and physiological data support the idea that CNS myelination is dependent on neuronal activity (Zalc and Fields, 2000). Reports have demonstrated the existence of glutamatergic and GABAergic synapses formed between neurons and NG2 cells (Bergles et al., 2000; Lin and Bergles, 2004). Synaptic transmission of NG2 cells is an attractive candidate for controlling proliferation and differentiation of these cells in an activity-dependent manner and thus for influencing CNS myelination, although direct evidence is lacking. Indeed, proliferating NG2 cells keep their

\footnotetext{
Received Jan. 14, 2010; revised March 19, 2010; accepted April 3, 2010.

This work was supported by young investigator grants from Agence Nationale de la Recherche and Fédération pour la Recherche sur le Cerveau. M.V.-F. was supported by fellowships from Région lle-de-France and Ligue Française contre la Sclérose en Plaques (LFSEP). A.M.B. was supported by the Biotech and Biological Sciences Research Council. We thank Boris Barbour and Serge Charpak for helpful discussions and comments on the manuscript. We also thank Dwight E. Bergles for the gift of NG2-DsRed transgenic mice.

Correspondence should be addressed to María Cecilia Angulo, Laboratoire de Neurophysiologie et Nouvelles Microscopies, Institut National de la Santé et de la Recherche Médicale, Unité 603, Centre National de la Recherche Scientifique, Unité Mixte de Recherche 8154, Université Paris Descartes, 45 Rue des Saints-Pères, 75006 Paris, France. E-mail: maria-cecilia.angulo@parisdescartes.fr.

DOI:10.1523/JNEUROSCI.0238-10.2010

Copyright $\odot 2010$ the authors $\quad 0270-6474 / 10 / 306921-09 \$ 15.00 / 0$
}

synapses and transfer them to their progeny during cell division (Kukley et al., 2008; Ge et al., 2009). In addition, there is an increasing axonal glutamatergic "synaptic-like" activity in NG2 cells of the corpus callosum that evolves in parallel with the maturation of the white matter tract (Ziskin et al., 2007). In the hippocampus, glutamatergic synaptic activity also increases during the first three postnatal weeks (Mangin et al., 2008). However, although GABAergic synapses have been reported in NG2 cells (Lin and Bergles, 2004; Jabs et al., 2005; Karadottir et al., 2008; Tanaka et al., 2009), GABAergic transmission during postnatal development has not been studied to date. Yet, GABA is one of the most predominant neurotransmitters during brain development and controls cell cycle kinetics of neocortical precursor cells by acting on $\mathrm{GABA}_{\mathrm{A}}$ receptors (LoTurco et al., 1995; Nguyen et al., 2001).

Here we examined the synaptic properties of NG2 cells in the barrel cortex during the first postnatal month, i.e., the period of active myelination in the neocortex (Bjelke and Seiger, 1989; Salami et al., 2003). We found that synaptic activity of cortical NG2 cells is predominantly GABAergic in the second $\mathrm{PN}$ week and dramatically decreases thereafter. However, the developmental loss of direct GABAergic synaptic transmission of cortical NG2 cells is replaced by an extrasynaptic mode of communication mediating phasic responses in which $\mathrm{GABA}_{\mathrm{A}}$ receptors are activated by pure GABA spillover. This mode of spillover or volume transmission mediates sustained GABAergic responses in NG2 cells during repetitive neuronal stimulation in the range of gamma oscillations that occur naturally in vivo, suggesting that interneurons signal to NG2 cells during sensory processing. 


\section{Materials and Methods}

Slice preparation. All experiments followed European Union and institutional guidelines for the care and use of laboratory animals. Acute parasagittal slices $(300 \mu \mathrm{m})$ of the barrel cortex with an angle of $10^{\circ}$ to the sagittal plane were obtained from NG2-DsRed BAC transgenic mice (Ziskin et al., 2007) at postnatal day 3 (PN3) to PN28. Slices were prepared in an ice-cold solution containing the following (in $\mathrm{mM}$ ): 215 sucrose, $2.5 \mathrm{KCl}, 1.25 \mathrm{NaH}_{2} \mathrm{PO}_{4}, 26 \mathrm{NaHCO}_{3}, 20$ glucose, 5 pyruvate, 1 $\mathrm{CaCl}_{2}$, and $7 \mathrm{MgCl}_{2}\left(95 \% \mathrm{O}_{2}, 5 \% \mathrm{CO}_{2}\right)$; the slices then were incubated for $20 \mathrm{~min}$ at $33^{\circ} \mathrm{C}$ in a solution containing $126 \mathrm{~mm} \mathrm{NaCl}$ instead of sucrose and $1 \mathrm{~mm} \mathrm{MgCl} 2$ and $2 \mathrm{~mm} \mathrm{CaCl}_{2}$. Finally, the slices were transferred to a recording chamber perfused with the same solution at 2-3 $\mathrm{ml} / \mathrm{min}$ and at $30-32^{\circ} \mathrm{C}$.

Electrophysiology. NG2 cells were identified by detecting DsRed fluorescence using $560 \mathrm{~nm}$ excitation and $620 \mathrm{~nm}$ emission wavelengths and visualized using IR-DIC video microscopy. Excitation and emission wavelengths for DsRed were obtained by using 560 and $620 \mathrm{~nm}$ filters, respectively. Patch pipettes were filled with an intracellular solution containing the following (in mM): $130 \mathrm{CsCl}, 104$-AP, 5 tetraethylammonium chloride (TEA-Cl), 5 EGTA, $0.5 \mathrm{CaCl}_{2}, 2 \mathrm{MgCl}_{2}, 10$ HEPES, $2 \mathrm{Na}_{2} \mathrm{ATP}$, $0.2 \mathrm{Na}$-GTP, $10 \mathrm{Na}_{2}$-phosphocreatine, $\mathrm{pH} \approx 7.3$ ). In some experiments, $1 \mathrm{~mm}$ extracellular $\mathrm{Ba}^{2+}$ was added in the perfusate to increase the membrane resistance of recorded cells (Velez-Fort et al., 2009). Recordings were made without series resistance $\left(R_{\mathrm{s}}\right)$ compensation $\left[R_{\mathrm{s}}=10.1 \pm 0.6\right.$ $\mathrm{m} \Omega(n=25)$ and $R_{\mathrm{s}}=11.6 \pm 0.9 \mathrm{~m} \Omega(n=22)$ in the second and fourth PN weeks, respectively; $p>0.05]$. Series resistances were monitored during recordings, and cells showing a change of $>30 \%$ were discarded. Extracellular stimulations were obtained using a monopolar electrode placed in layer $\mathrm{V}$ of the barrel cortex in a position that evoked stable responses $(100 \mu \mathrm{s} ; 2-40 \mathrm{~V}$ at a rate of $0.025-0.1 \mathrm{~Hz}$; Iso-Stim 01D, NPI Electronic).

Analysis. Whole-cell recordings of NG2 cells were obtained using MultiClamp 700B (Molecular Devices), filtered at $2-4 \mathrm{kHz}$, and digitized at $10-20 \mathrm{kHz}$. Digitized data were analyzed off-line using pClamp 10.1 software (Molecular Devices). Spontaneous and miniature synaptic currents were recorded at a holding potential of $-90 \mathrm{mV}$, detected with a detection threshold of 4 times SD, and rise times $\left(t_{10-90 \%}\right)<3$ ms. For detection of spontaneous GABAergic slow currents, we analyzed cells recorded between 6 and $18 \mathrm{~min}$. For extracellular stimulations, cells were recorded at a holding potential of $-70 \mathrm{mV}$, and traces not showing evoked responses larger than 2 times the SD were considered as failures. It is noteworthy that we clamped the cells at $-90 \mathrm{mV}$ when studying spontaneous synaptic events to increase the driving force of synaptic currents and, thus, the chance of detecting spontaneous events. Instead, we used $-70 \mathrm{mV}$ to study evoked currents because these experiments required a longer recording time, sometimes $1 \mathrm{~h}$, and cells were healthier at this potential. The paired-pulse ratio was estimated by averaging 20-75 sweeps; the current amplitude at the second pulse was estimated after subtracting the decay of the current elicited at the first pulse. The mean rise times of evoked currents were calculated by averaging the synaptic responses excluding failures. The voltage-jump technique was adapted from Szapiro and Barbour (2007). The averaged evoked currents at each potential and at the jump was estimated by averaging $14-50$ sweeps. The frequency of evoked miniature events obtained by replacing $\mathrm{Ca}^{2+}$ by $\mathrm{Sr}^{2+}$ was calculated during $3 \mathrm{~s}$ after stimulation. No or very few events were observed before the stimulation in $\mathrm{Sr}^{2+}$. In experiments with NNC711 $(10 \mu \mathrm{M}$ ), currents elicited by trains of stimuli (10 pulses at 100 $\mathrm{Hz}$ ) were low-pass filtered at $100 \mathrm{~Hz}$ to eliminate the stimulation artifacts. Then, the charge of the averaged traces in control conditions and in NNC711 was measured over $500 \mathrm{~ms}$ from the current onset.

Morphology. Recorded NG2 cells were injected for 15-20 min with 5.4 $\mathrm{mm}$ biocytin contained in the intracellular solution. Slices were then fixed overnight in $4 \%$ paraformaldehyde at $4^{\circ} \mathrm{C}$ and biocytin was revealed with Alexa-488-conjugated streptavidin for $4 \mathrm{~h}$ at room temperature. Images were acquired on a LSM 510 metaconfocal microscope (Zeiss) using a $\times 40$ oil-immersion lens with high numerical aperture (1.3). Fluorescence was visualized at $488 \mathrm{~nm}$ (green) using an argon laser. A pinhole of one airy unit or less was used, with an average of four scans per image, and the number of $z$-sections and resolution were optimized using the Zeiss acquisition software. Image visualization and analysis was performed using Volocity4 software (Improvision, PerkinElmer). Reiterative restoration (deconvolution) was performed to reduce background and improve the signal:noise ratio. Measurements of cell volume were made of voxels in three dimensions using Volocity4.

Calcium imaging. Slices of the barrel cortex were loaded with the cellpermeant $\mathrm{Ca}^{2+}$ indicator Oregon Green BAPTA-1AM (11 $\left.\mu \mathrm{M}\right)$ for $1 \mathrm{~h}$ at $33^{\circ} \mathrm{C}$. Changes in intracellular $\mathrm{Ca}^{2+}$ concentrations upon muscimol (50 $\mu \mathrm{M})$ applications in the presence of a mixture of antagonists were assessed using an Olympus BX51 microscope equipped with $40 \times$ fluorescent water-immersion objective. Excitation light was provided by an OptoLED light source (Blue OptoLED; Cairn Research), and images were collected with an iXon cooled $\left(-80^{\circ} \mathrm{C}\right)$ 14-bit digital camera (Andor Technology). Excitation and emission wavelengths were obtained by using 470 and $525 \mathrm{~nm}$ filters, respectively. The Imaging Workbench 6.0 software (Indec Biosystems) was used to acquire and store images for off-line analysis. Exposure times were $20-50 \mathrm{~ms}$ and images were collected at 2-4 Hz. The background fluorescence was subtracted, and $\mathrm{Ca}^{2+}$ responses were expressed as relative changes in fluorescence $(\Delta F / F)$.

Statistics. Data are expressed as mean \pm SEM. The nonparametric Mann-Whitney $U$ test for independent samples was used to determine statistical differences between data obtained in the second and fourth postnatal weeks. When comparisons within single cells were required, the Wilcoxon signed-rank test for related samples was used (GraphPad InStat software, version 3.06). The correlation between cell membrane resistance and synaptic current frequency was tested with the Pearson $r$ test. Cumulative distributions of rise times were compared using the Kolmogorov-Smirnov test.

\section{Results}

Spontaneous GABAergic synaptic activity of cortical NG2 cells decreases during postnatal development

Whole-cell recordings of DsRed ${ }^{+} \mathrm{NG} 2$ cells were performed with a CsCl-based intracellular solution containing 4-AP and TEA-Cl in layer $\mathrm{V}$ of the barrel cortex of NG2-DsRed transgenic mice (Ziskin et al., 2007) during the first postnatal month. As shown in Figure 1, $a$ and $b$, spontaneous inward synaptic currents, recognized by their fast rise time, were detected after PN3 in NG2 cells held at $-90 \mathrm{mV}$ (see Materials and Methods). The frequency of these synaptic currents, however, dramatically decreased after the second PN week (Fig. $1 a-c$ ). The NG2 cell membrane resistance also decreased during development [from $638.8 \pm 121.2 \mathrm{M} \Omega$ $(n=25)$ to $137.8 \pm 42.5 \mathrm{M} \Omega(n=22)$ in the second and fourth PN weeks, respectively; $p<0.001]$. Although the membrane resistance remained relatively high in our recording conditions, the apparent reduction in synaptic activity might be caused by a decrease of the membrane space constant and thus by a filtering of postsynaptic currents at later developmental stages. However, no correlation was observed between synaptic current frequency and membrane resistance of cortical NG2 cells (Fig. 1d). Additionally, no significant developmental changes in morphology were observed between the second and fourth PN weeks (supplemental Fig. 1, available at www.jneurosci.org as supplemental material) $(p>0.05)$.

NG2 cells receive direct glutamatergic and GABAergic synaptic inputs from neurons in the hippocampus (Bergles et al., 2000; Lin and Bergles, 2004; Jabs et al., 2005), and thus pharmacological experiments were performed to discriminate synaptic currents mediated by glutamate and GABA in the barrel cortex. The $\mathrm{GABA}_{\mathrm{A}}$ receptor antagonist SR95531 $(5 \mu \mathrm{M})$ blocked $>90 \%$ of spontaneous synaptic activity in the second postnatal week, indicating that most of this activity was GABAergic early in postnatal life (Fig. 1e). At the later developmental stage, SR95531 did not change significantly the frequency of the few remaining fast spon- 
a

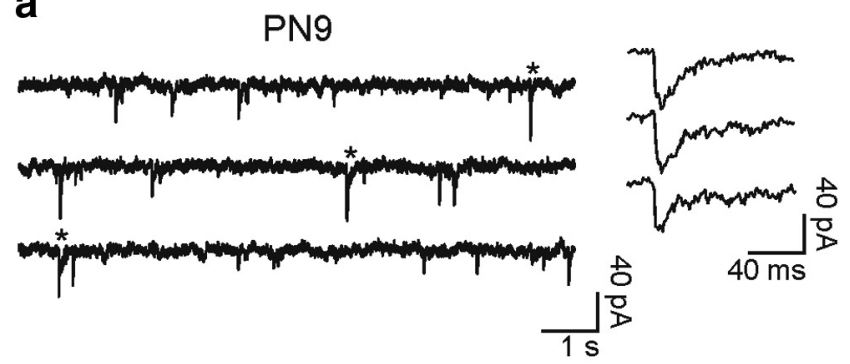

C

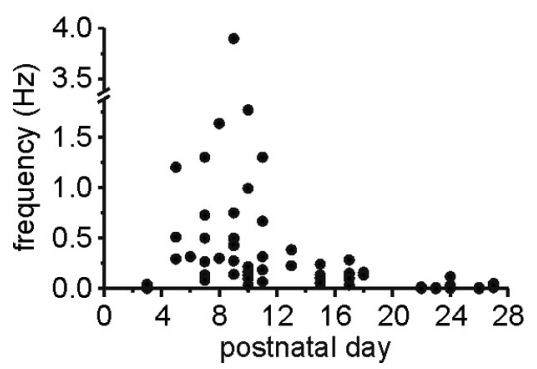

b

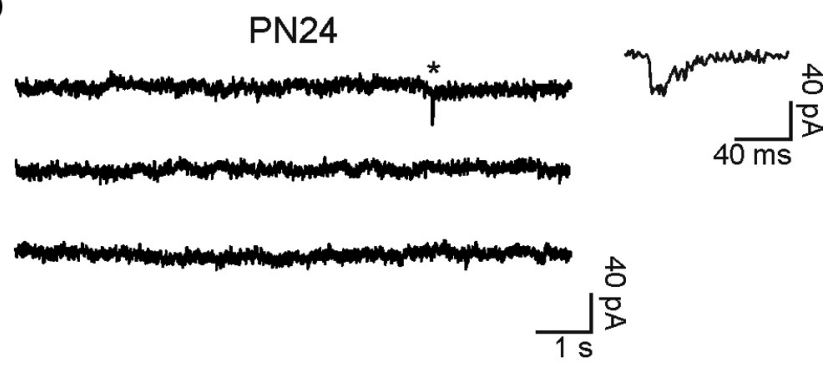

e

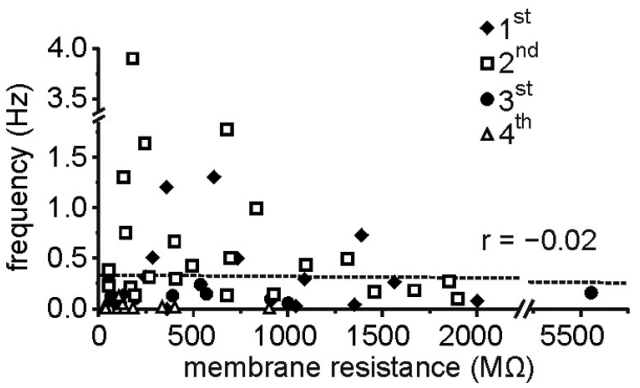

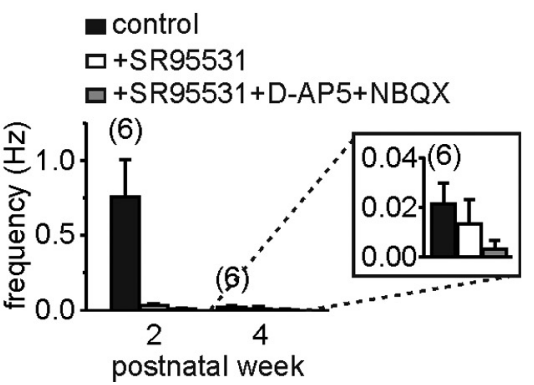

Figure 1. Decrease of spontaneous synaptic activity of NG2 cells during postnatal development. $\boldsymbol{a}$ and $\boldsymbol{b}$, Spontaneous synaptic currents of two NG2 cells held at $-90 \mathrm{mV}$ at PN9 ( $\boldsymbol{a}$ ) and PN24 (b). Note the fast rise times of individual currents at both ages $(<2.1 \mathrm{~ms})$. c, Plot of spontaneous synaptic current frequency against PN day. $\boldsymbol{d}$, Plot of synaptic current frequency against cell membrane resistance. There was not a significant correlation between these two parameters $(r=-0.02 ; p>0.05)$. Each cell is marked with a different symbol according to its PN week. $\boldsymbol{e}$, Histogram of spontaneous synaptic current frequency in control, after bath application of $5 \mu \mathrm{m}$ SR95531, and after a further addition of $50 \mu \mathrm{m} \mathrm{D}-\mathrm{AP}-5$ and $10 \mu \mathrm{m} \mathrm{NBQX} \mathrm{for} \mathrm{the} \mathrm{second} \mathrm{and} \mathrm{fourth} \mathrm{PN} \mathrm{weeks.} \mathrm{Note}$ the absence of block by 5 Mm SR95531 in the fourth PN week (inset).

taneous events (Fig. 1e, inset); the large decrease of this spontaneous activity is thus probably caused by a loss of GABAergic synaptic currents during development. Consistent with data already reported in the neocortex (Chittajallu et al., 2004), the estimated frequency of glutamatergic synaptic currents was very low during the first postnatal month $(<0.033 \mathrm{~Hz})$ (Fig. 1e).

To test whether the decrease in GABAergic synaptic activity of cortical NG2 cells during development was accompanied by a loss of $\mathrm{GABA}_{\mathrm{A}}$ receptors, we applied in the bath a saturating concentration of the $\mathrm{GABA}_{\mathrm{A}}$ receptor agonist muscimol $(50 \mu \mathrm{M})$ in the presence of a mixture of antagonists for other ionotropic and metabotropic receptors (supplemental Fig. $2 a$, available at www. jneurosci.org as supplemental material). Similar current densities were observed in the presence of this agonist in the second and fourth PN weeks (supplemental Fig. 2b, available at www. jneurosci.org as supplemental material $)(p>0.05)$. The activation of $\mathrm{GABA}_{\mathrm{A}}$ receptors has been reported to produce a depolarizing effect on NG2 cells during different PN stages that increases intracellular $\mathrm{Ca}^{2+}$ concentration (Lin and Bergles, 2004; Tanaka et al., 2009; Tong et al., 2009). Calcium imaging experiments in slices loaded with the $\mathrm{Ca}^{2+}$ indicator Oregon Green BAPTA-1AM showed that muscimol, but not extracellular stimulation, induced $\mathrm{Ca}^{2+}$ signals at both developmental periods (supplemental Fig. $2 c-e$, available at www.jneurosci.org as supplemental material). The results demonstrate that NG2 cells still express functional $\mathrm{GABA}_{\mathrm{A}}$ receptors at the end of the first PN month.

Finally, we analyzed the frequency of miniature GABAergic synaptic currents of NG2 cells in the presence of the $\mathrm{Na}^{+}$ channel blocker tetrodotoxin (TTX), the AMPA/kainate antagonist 2,3-dioxo-6-nitro-1,2,3,4-tetrahydro-benzo[f] quinoxline7-sulfonamide (NBQX), and the NMDA antagonist D-AP-5. Miniature synaptic events were detected in the second PN week $(0.027 \pm 0.005 \mathrm{~Hz} ; n=4)$. Averaged miniature GABAergic syn- aptic currents had a peak amplitude of $-12.8 \pm 3.3 \mathrm{pA}$, a rise time $\left(t_{10-90 \%}\right)$ of $1.0 \pm 0.1 \mathrm{~ms}$, and a decay time fitted with a single exponential function of $15.3 \pm 2.9 \mathrm{~ms}$. In contrast, only one miniature current was observed in four cells of the fourth PN week. Together, these results showed a strong reduction of GABAergic synaptic activity after the second PN week.

Properties of evoked GABAergic currents in NG2 cells change during postnatal development

The presence of functional $\mathrm{GABA}_{\mathrm{A}}$ receptors and the dramatic decrease of spontaneous GABAergic synaptic activity during development prompted us to study the mechanisms of activation of these receptors by evoked neuronal activity in the second and fourth PN weeks. Low-frequency stimulations $(0.025-0.1 \mathrm{~Hz})$ were applied with an extracellular electrode placed in layer $\mathrm{V}$ of cortical slices, while NG2 cells were recorded in voltage clamp at $-70 \mathrm{mV}$ in the presence of NBQX and D-AP-5 to block glutamatergic activity. Similar extracellular stimulations in neurons induced current densities $9.3 \pm 2.4$ larger than those in NG2 cells ( $n=10$; comparison between the second and fourth PN weeks in supplemental Fig. 3, available at www.jneurosci.org as supplemental material). $\mathrm{GABA}_{\mathrm{A}}$ receptor-mediated currents, sensitive to SR95531 and reversing near $0 \mathrm{mV}$, were easily elicited at both postnatal periods (Fig. 2a,b). However, the properties of the evoked currents were different between the second and fourth PN weeks. Although a paired-pulse depression was observed at both developmental stages, stimulation elicited currents in NG2 cells of older mice with fewer failures of transmission and less current amplitude variability, as quantified by the coefficient of variation (supplemental Table 1, available at www.jneurosci.org as supplemental material). Moreover, evoked GABAergic currents had unusually very slow rise times at later stages (Fig. $2 c)\left[t_{10-90 \%}=\right.$ $1.5 \pm 0.1 \mathrm{~ms}(n=28)$ and $t_{10-90 \%}=7.2 \pm 1.1 \mathrm{~ms}(n=18)$ in the second and fourth PN weeks, respectively; $p<0.001]$. Similar 
slow transient $\mathrm{GABA}_{\mathrm{A}}$ receptor currents occurred spontaneously in cells of the fourth $\mathrm{PN}$ week, i.e., in the absence of electrical stimulation (Fig. $2 d$ ). In six of twelve NG2 cells recorded in the presence of NBQX and D-AP-5, we detected spontaneous slow rising currents that had a mean rise time of $5.1 \pm 0.7 \mathrm{~ms}$, a peak amplitude of $18.1 \pm 5 \mathrm{pA}$, and a decay time of $18.8 \pm 2.5 \mathrm{~ms}$ (Fig. $2 d$ ). The frequency of these slow transient events was, however, very low $(0.005 \pm 0.003 \mathrm{~Hz})$; only one slow transient current was observed in the presence of SR95531 (5 $\mu \mathrm{M}$; $n=5$; duration of the recordings: from 6 to $18 \mathrm{~min}$ ).

The observed prolonged responses could result from considerable distortion and attenuation of signals occurring as a consequence of an inadequate space clamp (Pearce, 1993; Szapiro and Barbour, 2007). The slow kinetics of evoked responses during development may thus be a consequence of the displacement of synaptic contacts to distant electrotonic sites during development. First, we tested whether the rise times of the responses were accelerated by increasing the membrane resistance in older mice with 1 $\mathrm{mm}$ extracellular $\mathrm{Ba}^{2+}$ in the perfusate $[137.8 \pm 42.5 \mathrm{M} \Omega$ in control $(n=22)$ vs $938.2 \pm 166.2 \mathrm{M} \Omega$ in presence of $\mathrm{Ba}^{2+}$ $(n=15)$ ] (Velez-Fort et al., 2009). Even in conditions with high membrane resistances, evoked currents at the fourth PN week maintained slow rise times, similar to those recorded without $\mathrm{Ba}^{2+}\left[t_{10-90 \%}=9.5 \pm 1.8 \mathrm{~ms}\right.$ in $\left.\mathrm{Ba}^{2+}(n=15) ; p>0.05\right]$. It is also noteworthy that evoked currents obtained in this optimal clamp condition showed slower weighted decay times than those recorded in similar clamp conditions in younger mice $[\tau=$ $52.3 \pm 12.0 \mathrm{~ms}$ in $\mathrm{Ba}^{2+}$ in the fourth PN week mice $(n=13)$ vs $\tau=32.2 \pm 1.9 \mathrm{~ms}$ without $\mathrm{Ba}^{2+}$ in the second $\mathrm{PN}$ week mice $(n=$ $20) ; p<0.05]$. Second, we used the voltage-jump technique to examine whether slow evoked currents in older mice were caused by a genuinely long-lasting conductance or a brief conductance subjected to considerable filtering (Pearce, 1993; Szapiro and Barbour, 2007). As shown in Figure 3, $a$ and $b$, the voltage jump method consisted of applying a voltage step of $-30 \mathrm{mV}$ during the evoked responses of cells held at $-40 \mathrm{mV}$ to increase the driving force (see Materials and Methods). The averaged current obtained after subtracting the capacity transients was then compared with those elicited at constant holding potentials of -40 and $-70 \mathrm{mV}$ (Fig. $3 a, b$ ). The voltage jump rapidly changed the evoked currents, indicating that little distortion of the time course occurred and, therefore, that the GABAergic conductance was still active at the time of the step (Fig. $3 b)$. The time required by the current (10-90\%) during the voltage jump to reach the response at a steady-state holding potential of $-70 \mathrm{mV}\left(t_{\text {jump }}\right)$ was $1.2 \pm 0.4 \mathrm{~ms}$, always inferior to the rise time $\left(t_{10-90 \%}\right)$ of evoked currents (Fig. $3 c$ ). Hence, the slow rise times of evoked GABAergic responses in the fourth $\mathrm{PN}$ week were genuine and did not result from a strong filtering. $\mu \mathrm{M}$ NBQX and $50 \mu \mathrm{M}$ D-AP-5. b
PN8

SR95531

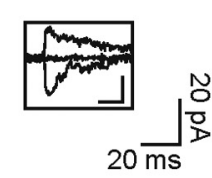

$20 \overline{\mathrm{ms}}$

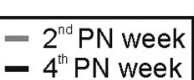

4 PN week

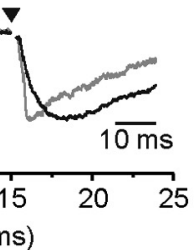

d

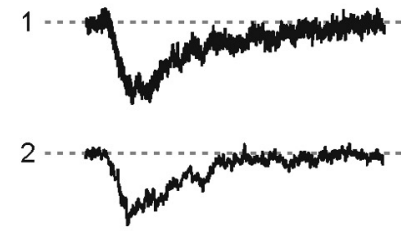

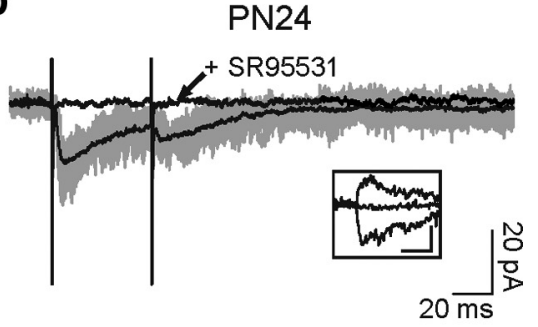

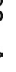

Figure 2. Evoked and spontaneous slow rising GABAergic currents for NG2 cells in the fourth PN week. $\boldsymbol{a}$ and $\boldsymbol{b}$, Paired-pulse ulation of neuronal fibers elicited inward currents in two NG2 cells held at $-70 \mathrm{mV}$ at PN8 (a) and PN24 (b), in the presence 列 arrowhead. $\boldsymbol{d}$, Spontaneous slow rising currents of two NG2 cells held at $-90 \mathrm{mV}$ at PN21 (1) and PN22 (2) in the presence of 10

GABAergic miniature currents are detectable for NG2 cells in the second but not in the fourth PN week

To test whether evoked currents come from GABA release at interneuron-NG2 cell synaptic contacts at both stages of development, we used $\mathrm{Sr}^{2+}$ to desynchronize vesicular release and isolate GABAergic miniature currents (Goda and Stevens, 1994). When replacing extracellular $\mathrm{Ca}^{2+}$ with $5 \mathrm{~mm} \mathrm{Sr}^{2+}$, a large decrease in the amplitude of evoked responses was observed, indicating that evoked currents resulted from the exocytotic release of GABA in the second and fourth PN weeks [ $82 \pm 10 \%(n=6)$ and $80 \pm 9 \%(n=7)$ of reduction, respectively] (Fig. $4 a, b)$. As expected for a synapse, asynchronous miniature events were apparent in all NG2 cells recorded in the second PN week $(n=6)$ (Fig. $4 c, e)$. Evoked miniature currents had a rise time of $1.4 \pm 0.4 \mathrm{~ms}$, a peak amplitude of $-15.7 \pm 1.3 \mathrm{pA}$, and a decay time described with a single exponential of $14.7 \pm 4.2 \mathrm{~ms}$, similar to those reported above for spontaneous miniature events (Fig. $4 e$, inset) $(p>0.05)$. However, a different behavior was observed in older mice, where almost no miniature events were observed (Fig. $4 d, e$ ) $(p<0.01)$.

To strengthen our observation showing that GABAergic miniature currents did not persist in the fourth $\mathrm{PN}$ week, we performed experiments in the presence of the potent secretagogue ruthenium red and of TTX, D-AP-5, and NBQX. As described for miniature GABAergic currents in NG2 cells of the hippocampus (Lin and Bergles, 2004), ruthenium red largely increased the postsynaptic current frequency in the second PN week. However, miniature events remained almost undetectable in the fourth PN week (Fig. $4 f)(p<0.01)$. The presence of extracellular $\mathrm{Ba}^{2+}$ in the perfusate, which increased the membrane resistance of recorded cells (Velez-Fort et al., 2009), did not further increase the 


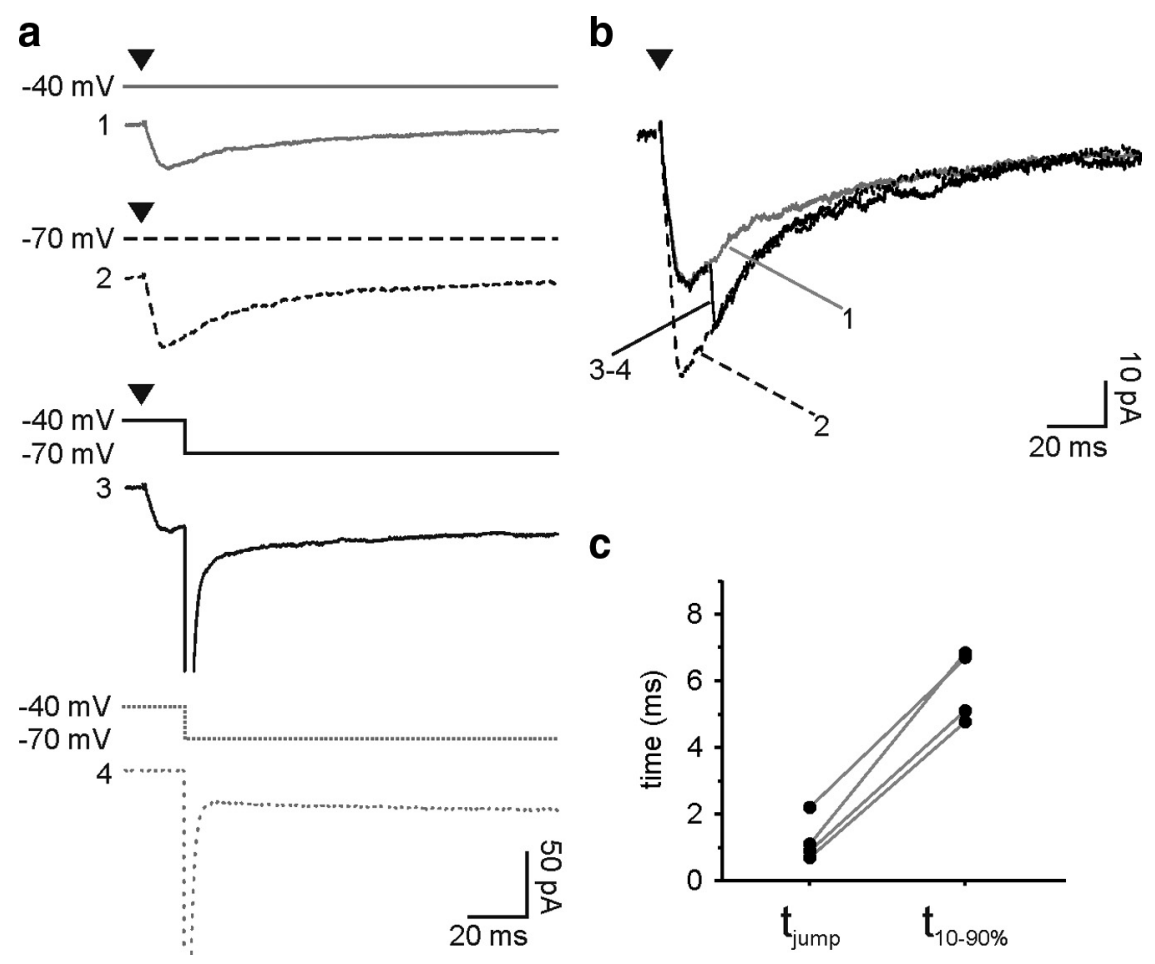

Figure 3. Slow kinetics of evoked GABAergic currents are not due to filtering. $\boldsymbol{a}$, Voltage jump protocol to test the speed of clamp of the synaptic conductance. Averaged currents evoked by extrasynaptic stimulation at a holding potential of $-40 \mathrm{mV}$ (solid gray) or $-70 \mathrm{mV}$ (dashed black) during voltage jumps from $-40 \mathrm{mV}$ to $-70 \mathrm{mV}$ (solid black) and averaged capacity transients recorded with a pulse of $-30 \mathrm{mV}$ from $-40 \mathrm{mV}$ (dashed gray). These experiments were done in the presence of $1 \mathrm{~mm} \mathrm{Ba}{ }^{2+}, 10 \mu \mathrm{m} \mathrm{NBQX}$ and $50 \mu \mathrm{m} \mathrm{D}-A \mathrm{AP}-5 . \boldsymbol{b}$, Superposition of the same averaged currents at a holding potential of $-40 \mathrm{mV}$ (solid gray) or $-70 \mathrm{mV}$ (dashed black) and after subtracting the capacity transients during voltage jumps from $-40 \mathrm{mV}$ to $-70 \mathrm{mV}$ (solid black). Note that the GABAergic conductance is still active during the voltage jump. Stimulus artifacts were blanked for visibility; the time of stimulation is indicated with an arrowhead. c, Plot comparing the time required by the current $(10-90 \%)$ to reach the response at $-70 \mathrm{mV}$ during the voltage jump ( $\left.t_{\text {jump }}\right)$ with the rise time $\left(t_{10-90 \%}\right)$ of averaged evoked currents at $-70 \mathrm{mV}$ in individual experiments.

apparent frequency of miniature events, demonstrating that in optimal space-clamp conditions miniature GABAergic synaptic currents are rarely observed in older mice (Fig. $4 f$ ). In conclusion, functional GABAergic synaptic contacts are lost during postnatal development of NG2 cells.

\section{A switch from synaptic to extrasynaptic transmission between interneurons and NG2 cells during development} Whereas fast $\mathrm{GABA}_{\mathrm{A}}$ receptor-mediated currents elicited in NG2 cells by low-frequency stimulation had all the features of direct synaptic transmission in the second PN week, the prolonged rise times of evoked responses as well as the rare number of miniature events observed in the fourth postnatal week strongly suggest that $\mathrm{GABA}_{\mathrm{A}}$ receptors in older mice were activated exclusively at extrasynaptic sites. Recently, an unusual mechanism of pure spillover transmission that induce phasic responses in the absence of classical synaptic activity has been described for neuronal connections in the cerebellum (Szapiro and Barbour, 2007) and the neocortex (Olah et al., 2009). By using pharmacological agents, we tested whether this mode of neuronal communication also controls GABAergic transmission from interneurons to NG2 cells in the barrel cortex after the second PN week.

Responses due to spillover are more sensitive to uptake blockers than synaptic ones. In the case of inhibitors of GABA transporters, two major effects have been described: a significant prolongation of the decay of $\mathrm{GABA}_{\mathrm{A}}$ receptor-mediated currents upon low-frequency stimulation (Rossi and Hamann, 1998;
Szabadics et al., 2007; Gonzalez-Burgos et al., 2009), and a large increase in current amplitudes upon high-frequency stimulation (Alle and Geiger, 2007; GonzalezBurgos et al., 2009). We thus analyzed the effect of the GAT-1 blocker NNC711 on $\mathrm{GABA}_{\mathrm{A}}$ receptor-mediated responses elicited by either a single pulse or a train of stimuli in the presence of the $\mathrm{GABA}_{\mathrm{B}}$ receptor antagonist CGP55845 $(5 \mu \mathrm{m})$ to exclude any effects of $\mathrm{GABA}_{\mathrm{B}}$ receptor activation. We considered that the comparison between young and older animals was valid since, although the expression of GAT-1 transporters increases during PN development of the neocortex, the protein levels in rodents are already $85 \%$ of the adult at PN10 (Conti et al., 2004). The decay of evoked currents upon lowfrequency stimulation was not changed in the second PN week (Fig. $5 a, c$ ), but became markedly prolonged in the fourth PN week (Fig. $5 b, c)(p<0.05)$. A 3.5fold increase of the decay time constant was observed in NNC711 in older mice. Additionally, trains of stimuli $(100 \mathrm{~Hz})$ resulted in a response that was potentiated by NNC711 in the fourth but not in the second PN week (Fig. $5 d-f)(p<0.05)$. Evoked responses in older mice are thus probably caused by GABA spillover rather than from direct synaptic terminals on NG2 cells.

If slowly evoked currents reflect the activation of extrasynaptic receptors by GABA diffusing a significant distance, the concentration reaching these receptors would be expected to be lower than that in the synaptic cleft. Therefore, the degree of inhibition of evoked responses by a low-affinity antagonist of $\mathrm{GABA}_{\mathrm{A}}$ receptors should be greater in the fourth than in the second PN week. Figure $6, a$ and $b$, illustrates the effect of the low-affinity competitive $\mathrm{GABA}_{\mathrm{A}}$ receptor antagonist $(1,2,5,6$ tetrahydropyridin-4-yl)methylphosphinic acid (TPMPA) (Jones et al., 2001) on responses elicited by single-pulse stimulations. The effect of TPMPA on the amplitude of averaged currents was significantly greater in the fourth PN week [amplitude decrease $81 \pm 7(n=6)$ vs $52 \pm 11(n=6)$ in the second and fourth PN week, respectively; $p<0.05$ ]. Assuming that the subunit composition of $\mathrm{GABA}_{\mathrm{A}}$ receptors is similar between the second and fourth week, these results suggest that lower GABA concentrations reached the receptors in older mice. In keeping with this assumption, the high affinity competitive antagonist SR95531 at low concentration (100 nM), which shows a slower unbinding time constant than TPMPA (Jones et al., 2001), decreased the evoked responses at both developmental stages similarly [amplitude decrease $59 \pm 11 \%(n=5)$ and $40 \pm 6 \%(n=5)$ at the second and fourth PN week, respectively; $p>0.05]$. Finally, we took advantage of the effect of TPMPA to test whether the slow transient currents reflect merely a loss of direct synaptic activation with age, instead of the appearance of a new mode of signaling in older animals. If slow transient currents are present in young mice, the kinetics of evoked responses should be faster when blocking the slow component with TPMPA. We observed 
that this is not the case, since the rise times were $1.7 \pm 0.3$ and $1.6 \pm 0.3 \mathrm{~ms}$ in control and TPMPA conditions, respectively $(n=$ $6 ; p>0.05)$. Therefore, there is probably a loss of direct synaptic activation and the appearance of a new transmission mode with age.

Together, our results demonstrate that, in contrast to classical synaptic transmission observed in NG2 cells of the second PN week, GABA released upon extracellular stimulation diffused to and exclusively activated distant $\mathrm{GABA}_{\mathrm{A}}$ receptors of these cells in the fourth $\mathrm{PN}$ week.

Differential effect of gamma-frequency stimulation on synaptic and spillover mediated NG2 cell currents

Whisker activation in rodents elicits gamma neuronal network activity in the barrel cortex (Jones and Barth, 1997), even as early as the first PN week (Yang et al., 2009). We thus compared the evoked currents mediated by synaptic and spillover transmission during repetitive gamma frequency neuronal stimulation $(50 \mathrm{~Hz}, 200$ $\mathrm{ms}$ ), a frequency pattern that is likely to be relevant in the somatosensory cortex in vivo (Ahissar and Vaadia, 1990; Jones and Barth, 1997). As expected for synaptic but not spillover transmission, individual signals within the train were more easily resolved for NG2 cells in the second PN week (Fig. 7a). Although a paired-pulse depression was observed at both developmental stages (Fig. 2a,b; supplemental Table 1, available at www.jneurosci.org as supplemental material), the longer duration of spillover-mediated currents in older mice led to a greater temporal summation of responses during a stimulus train (Fig. $7 b$ ). Thus, the ratio of the current reached at the end of the train $\left(\mathrm{I}_{\text {sum }}\right)$ over the initial current response $\left(\mathrm{I}_{1}\right)$ was almost two times larger in the fourth than in the second PN week $\left[\mathrm{I}_{\text {sum }} / \mathrm{I}_{1}\right.$ of $1,2 \pm 0,3(n=6)$ and $2,2 \pm 0,4$ $(n=6)$ in the second and fourth PN week, respectively; $p<0.05]$. In conclusion, GABA spillover allows a more efficient temporal summation in mature NG2 cells during neuronal bursts.

\section{Discussion}

We have reported here that the frequency of spontaneous and evoked miniature events in NG2 cells, which are predominantly GABAergic after the second postnatal week in the barrel cortex, dramatically decreases during development. However, this is not due to a developmental loss of functional $\mathrm{GABA}_{\mathrm{A}}$ receptors. Lowfrequency extracellular stimulation revealed that $\mathrm{GABA}_{\mathrm{A}}$ receptor activation of NG2 cells at later developmental stages mediates transient responses with unusually slow kinetics. The absence of miniature events as well as the higher sensitivity of evoked responses to NNC711 and TPMPA in the fourth PN week with respect to the second $\mathrm{PN}$ week supports the notion that $\mathrm{GABA}_{\mathrm{A}}$ the perfusate. b

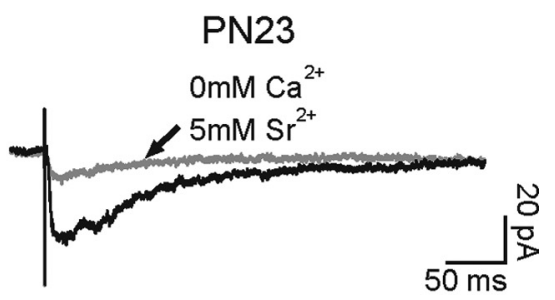

d

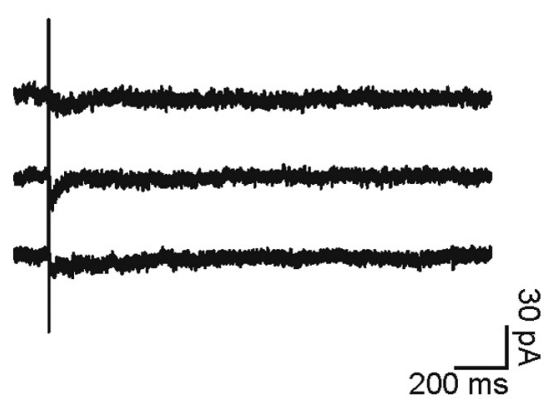

f

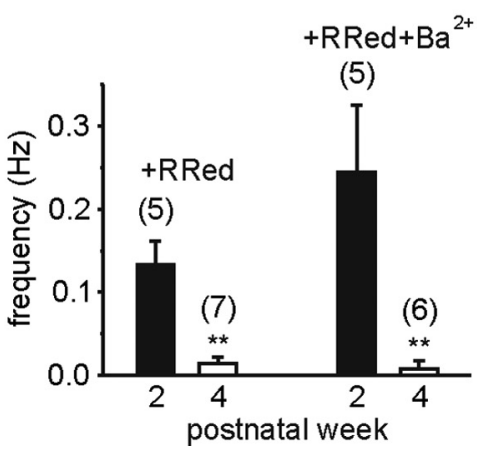

Figure 4. Miniature GABAergic synaptic currents of NG2 cells dramatically decrease during development. $\boldsymbol{a}$ and $\boldsymbol{b}$, Averaged traces of evoked currents of two NG2 cells held at $-70 \mathrm{mV}$ at PN11 (a) and PN23 $(\boldsymbol{b})$ in control (black) and when $2 \mathrm{~mm} \mathrm{Ca}^{2+}$ was replaced by $5 \mathrm{~mm} \mathrm{Sr}^{2+}$ (gray). In these experiments, $10 \mu \mathrm{m} \mathrm{NBQX}$ and $50 \mu \mathrm{m}$ D-AP- 5 were added in the perfusate. Note that currents were strongly decreased in the presence of $\mathrm{Sr}^{2+}$ at both developmental stages. c and $\boldsymbol{d}$, Single traces of evoked currents of the same NG2 cells. Note the presence of miniature events with fast rise times at PN11 (c), but not at PN23 (d).e, Histogram of fequency of the evoked miniature events in $\mathrm{Sr}^{2+}$ for cells in the second and fourth PN weeks. The inset illustrates the average of the miniature events in the presence of $75 \mu \mathrm{m}$ ruthenium red (R Red) and $75 \mu \mathrm{m}$ ruthenium red plus $1 \mathrm{~mm} \mathrm{Ba}^{2}$ for cells in the second and fourth PN weeks. In these experiments, $0.5 \mu \mathrm{M} \mathrm{TTX,} 10 \mu \mathrm{M} \mathrm{NBQX}$, and $50 \mu \mathrm{m} \mathrm{D-AP-5}$ were also added in

receptor-mediated responses in NG2 cells from older mice arise from an extrasynaptic mode of diffuse transmission mediated solely by GABA spillover from neuronal terminals.

The extrasynaptic signaling between interneurons and NG2 cells of the barrel cortex has specific characteristics that differ from those between other glial cell types, in particular astrocytes (Perea et al., 2009) and Bergmann glia (Matsui and Jahr, 2003), as follows: (1) spillover effect on NG2 cells is mediated by ionotropic $\mathrm{GABA}_{\mathrm{A}}$ receptors; (2) although slower than direct synaptic events, spontaneous and evoked transient currents in NG2 cells occurred with a time course of few milliseconds; and (3) diffuse transmission in NG2 cells emerges after a loss of synaptic transmission and thus probably results from a rearrangement of interneuron-NG2 cell junctions during cortical network maturation. Because of these unique properties, spillover transmission between interneurons and NG2 cells can be considered as a novel mode of neuron-glia communication. 
a

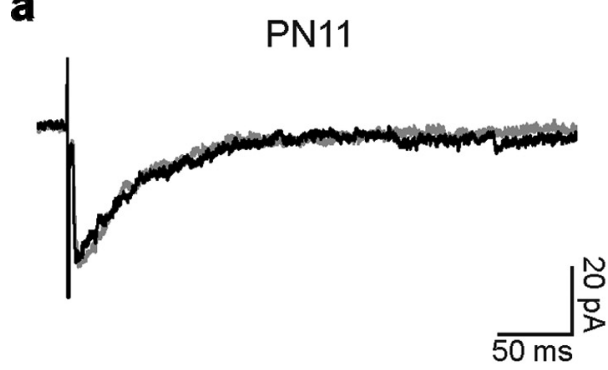

b

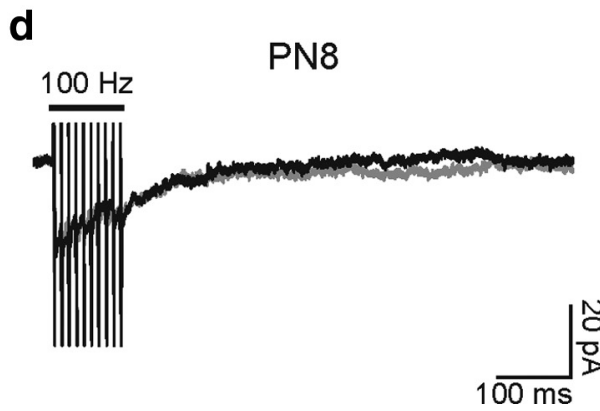

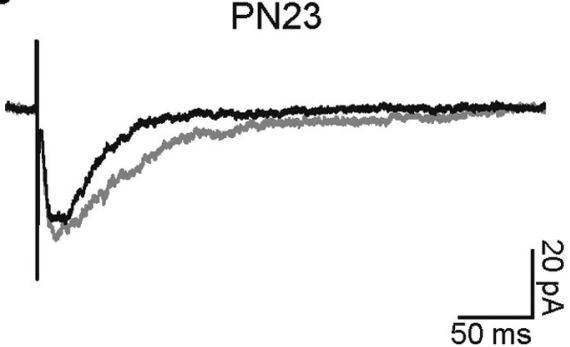

C

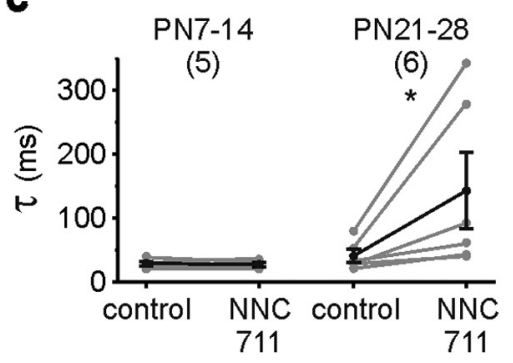

e

PN28 f

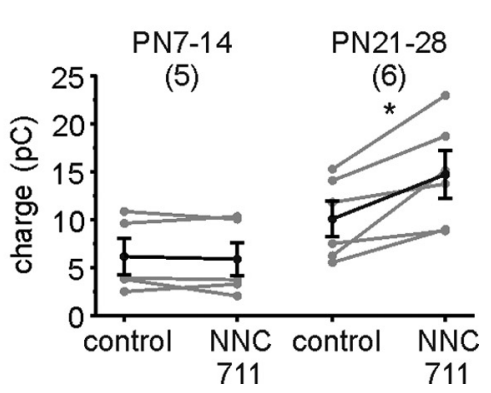

Figure 5. Interneuron-to-NG2 cell GABAergic transmission is sensitive to uptake blockers in the fourth PN week. $\boldsymbol{a}$ and $\boldsymbol{b}$, Averaged inward currents evoked by single stimuli in two NG2 cells held at $-70 \mathrm{mV}$ at PN11 (a) and PN23 (b) in control (black) and in the presence of $10 \mu \mathrm{m} \mathrm{NNC711} \mathrm{(gray).} \mathrm{In} \mathrm{these} \mathrm{experiments,} 10 \mu \mathrm{m} \mathrm{NBQX}$ and $50 \mu \mathrm{m}$ D-AP-5 were present in the perfusate. Note the increase in the decay time constant at PN23, but not at PN11. c, Effect of $10 \mu \mathrm{m}$ NNC711 on the decay time constant $(\tau)$ of individual experiments in the second and the fourth PN week. $\boldsymbol{d}$ and $\boldsymbol{e}$, Averaged inward currents evoked by trains of stimuli (10 pulses at $100 \mathrm{~Hz}$ ) in two NG2 cells held at $-70 \mathrm{mV}$ at PN8 (d) and PN28 (e) in control (black) and in the presence of $10 \mu \mathrm{m} \mathrm{NNC711} \mathrm{(gray).}$ Note the large increase in the amplitude at PN28, but not at PN8.f, Effect of $10 \mu \mathrm{m} \mathrm{NNC711} \mathrm{on} \mathrm{the} \mathrm{charge} \mathrm{integrated} \mathrm{over} 500 \mathrm{~ms}$ from the first stimulation in the second and the fourth postnatal weeks.

a

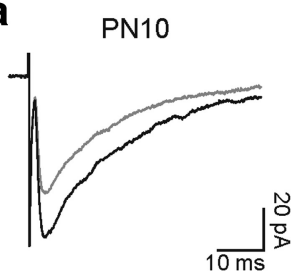

b

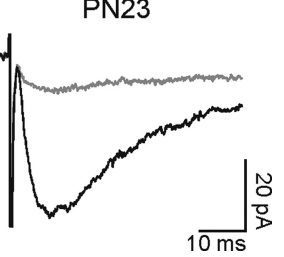

Figure 6. Effects of the low-affinity antagonist TPMPA on evoked $G A B A_{A}$ receptor-mediated responses during development. $\boldsymbol{a}$ and $\boldsymbol{b}$, Average inward currents evoked by single stimuli in two NG2 cells held at $-70 \mathrm{mV}$ at PN10 (a) and PN23 $(\boldsymbol{b})$ in control (black) and in the presence of $100 \mu \mathrm{m}$ TPMPA (gray). In these experiments, $10 \mu \mathrm{m}$ NBQX and $50 \mu \mathrm{m} \mathrm{D}-\mathrm{AP}-5$ were added in the perfusate. Note the stronger inhibition at PN23 with respect to PN10. rents in adult animals resulted from a direct synaptic innervation between interneurons and NG2 cells, without testing for a genuine synaptic response. They reported low-frequency spontaneous currents with prolonged rise times $(4.7 \mathrm{~ms})$ similar to those observed here $(5.1 \mathrm{~ms})$, which are not compatible with values expected for classical synaptic currents ( $\leq 1 \mathrm{~ms}$ ) (Farrant and Nusser, 2005). By using the voltage jump technique, we demonstrated that slow kinetics of GABAergic responses did not result from signal filtering. Our results also argue against slow kinetics caused by direct synaptic asynchronous release on NG2 cells, since asynchronous synaptic events were never resolved during the rising phase of evoked currents, and single miniature events were almost undetectable in the presence of strontium or ruthe- a

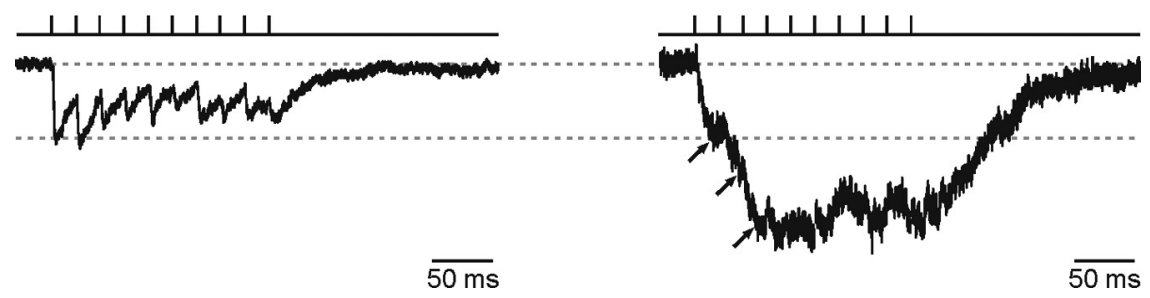

Figure 7. Effect of gamma frequency stimulation on evoked $G_{A B} A_{A}$ receptor-mediated currents during development. $\boldsymbol{a}$ and $\boldsymbol{b}$, Inward currents elicited by gamma frequency $(50 \mathrm{~Hz})$ train stimulation of neuronal fibers in two NG2 cells held at $-70 \mathrm{mV}$ at PN11 (a) and PN25 (b) in the presence of $10 \mu \mathrm{m} \mathrm{NBQX}$ and $50 \mu \mathrm{m} \mathrm{D}$-AP-5. Both currents were normalized at the first stimulation pulse. Traces in SR95531 were subtracted to the trace control (average of five traces in each case); artifacts were blanked. The current peaks reached at the first three stimulation pulses for the cell at PN25 are indicated (arrows). Note the presence of single synaptic events within the train in the second PN week and the larger temporal summation of spillover-mediated currents in the fourth PN week.

Low-frequency spontaneous currents and electrically evoked responses mediated by $\mathrm{GABA}_{\mathrm{A}}$ receptors were recently described in cortical nestin ${ }^{+} / \mathrm{NG}^{+}{ }^{+}$cells of 8 -week-old mice (Tanaka et al., 2009). The authors assumed that the observed GABAergic curnium red. Nevertheless, we cannot entirely exclude that GABAergic activity of cortical NG2 cells arises from asynchronous release from remote neuronal synapses. Finally, we cannot totally exclude that changes in the subunit composition of $\mathrm{GABA}_{\mathrm{A}}$ receptors expressed in NG2 cells partially explain the slowdown kinetics of GABAergic responses during development.

The release of GABA from a synaptic terminal induces a rapid activation of receptors at adjacent postsynaptic densities (Farrant and Nusser, 2005), as observed in cortical NG2 cells of the second PN week. In fact, the presence of neuronal glutamatergic and GABAergic synaptic-like contacts on these cells has been found by electron microscopy in different structures of the CNS (Bergles et al., 2000; Lin and Bergles, 2004; Lin et al., 2005; Kukley et al., 2007; Ziskin et al., 2007). However, our results raise questions about the anatomical and functional junctions formed between interneurons and NG2 
cells in the adult. The three-dimensional reconstruction and quantification of interneuron and NG2 cell membrane appositions at different developmental PN stages of the barrel cortex would be of particular interest to understand the morphological changes carrying out the switch from synaptic to extrasynaptic transmission mode. GABA spillover appears to be a reliable mechanism to activate $\mathrm{GABA}_{\mathrm{A}}$ receptors of NG2 cells in the millisecond scale and, therefore, GABA probably diffuses over relatively short distances from the neuronal synapses shown to be directly apposed to NG2 cell membranes (Farrant and Nusser, 2005). The lack of a tonic current accompanying spillover phasic responses [current amplitude blocked by $5 \mu \mathrm{M}$ SR95531: $0.3 \pm$ $6.1 \mathrm{pA}(n=6)$ and $2.5 \pm 9.8 \mathrm{pA}(n=4)$ in the second and fourth $\mathrm{PN}$ weeks, respectively] also supports the view that a widespread diffusion of transmitter does not take place and that it occurs at local sites on NG2 cell membranes. Interestingly, a pure glutamate spillover transmission has been described in climbing fiberinterneuron connections (Szapiro and Barbour, 2007). Ultrastructural analyses of climbing fiber terminals and molecular layer interneurons have shown tight membrane appositions external to but in the region of active zones (Kollo et al., 2006), which provides an indirect morphological support for glutamate spillover transmission at these particular junctions. In addition, a recent report showed that cortical neurogliaform interneurons do not require direct synaptic junctions to induce unitary GABAmediated responses in target neurons (Olah et al., 2009), corroborating our evidence that pure spillover connections may constitute a precise phasic mode of communication between interneurons and NG2 cells in the mature brain.

Recent reports have shown that, during cell division, NG2 cells maintain their glutamatergic and GABAergic synapses and transfer them to their progeny (Kukley et al., 2008; Ge et al., 2009). Although the function of NG2 cell synapses is not known, there is an emerging idea that direct synaptic activity may influence NG2 cell proliferation and differentiation (Nishiyama et al., 2009). Additionally, synaptic $\mathrm{GABA}_{\mathrm{A}}$ receptor activation may induce NG2 cell migration through activation of a Na ${ }^{+}$channel$\mathrm{Na}^{+} / \mathrm{Ca}^{2+}$ exchanger pathway (Tong et al., 2009). Our results in the barrel cortex support the hypothesis that direct synaptic activity has a developmental function in NG2 cells, since the frequency of spontaneous GABAergic synaptic activity dramatically decreases after the second postnatal week, which corresponds with the peak period of oligodendrocyte differentiation (Baracskay et al., 2002) and active myelination (Bjelke and Seiger, 1989; Salami et al., 2003). However, we show that as development in the neocortex nears completion, GABAergic signaling onto NG2 cells is not lost, but instead there is developmental switch from synaptic transmission to spillover transmission. Hence, if $\mathrm{GABA}_{\mathrm{A}}$ receptors are important in regulating NG2 cell differentiation, then the mode of transmission must be critical, and it will be worth examining whether there is a return to synaptic transmission in pathology such as demyelination. In addition, NG2 cells may have unresolved physiological functions, and spillover transmission would allow NG2 cells to integrate neuronal network activity patterns occurring during sensory processing. We found that gamma frequency neuronal activity evoked sustained extrasynaptic responses in NG2 cells. Although extracellular stimulation in brain slices does not necessarily mimic the spatial patterns of activity that occur in vivo and may favor spillover mechanisms with respect to more physiological conditions, our results are consistent with the possibility that interneurons signal to NG2 cells during sensory-evoked gamma oscillations in vivo. A pure
GABA spillover transmission may constitute a signaling mechanism to maintain NG2 cells as differentiated cells but may also play an important role in pathological processes. Indeed, GABA promotes the production of BDNF in cortical NG2 cells after ischemic stroke, suggesting a neuroprotective role of these cells in injured areas (Tanaka et al., 2009). Although NG2 cells serve as precursors for oligodendrocytes during early postnatal development, our results suggest that these cells play additional roles in the adult.

\section{References}

Ahissar E, Vaadia E (1990) Oscillatory activity of single units in a somatosensory cortex of an awake monkey and their possible role in texture analysis. Proc Natl Acad Sci U S A 87:8935-8939.

Alle H, Geiger JR (2007) GABAergic spill-over transmission onto hippocampal mossy fiber boutons. J Neurosci 27:942-950.

Baracskay KL, Duchala CS, Miller RH, Macklin WB, Trapp BD (2002) Oligodendrogenesis is differentially regulated in gray and white matter of jimpy mice. J Neurosci Res 70:645-654.

Bergles DE, Roberts JD, Somogyi P, Jahr CE (2000) Glutamatergic synapses on oligodendrocyte precursor cells in the hippocampus. Nature 405:187-191.

Bjelke B, Seiger A (1989) Morphological distribution of MBP-like immunoreactivity in the brain during development. Int J Dev Neurosci 7:145-164.

Chang A, Nishiyama A, Peterson J, Prineas J, Trapp BD (2000) NG2positive oligodendrocyte progenitor cells in adult human brain and multiple sclerosis lesions. J Neurosci 20:6404-6412.

Chittajallu R, Aguirre A, Gallo V (2004) NG2-positive cells in the mouse white and grey matter display distinct physiological properties. J Physiol 561:109-122.

Conti F, Minelli A, Melone M (2004) GABA transporters in the mammalian cerebral cortex: localization, development and pathological implications. Brain Res Brain Res Rev 45:196-212.

Farrant M, Nusser Z (2005) Variations on an inhibitory theme: phasic and tonic activation of GABA(A) receptors. Nat Rev Neurosci 6:215-229.

Ge WP, Zhou W, Luo Q, Jan LY, Jan YN (2009) Dividing glial cells maintain differentiated properties including complex morphology and functional synapses. Proc Natl Acad Sci U S A 106:328-333.

Goda Y, Stevens CF (1994) Two components of transmitter release at a central synapse. Proc Natl Acad Sci U S A 91:12942-12946.

Gonzalez-Burgos G, Rotaru DC, Zaitsev AV, Povysheva NV, Lewis DA (2009) GABA transporter GAT1 prevents spillover at proximal and distal GABA synapses onto primate prefrontal cortex neurons. J Neurophysiol 101:533-547.

Guo F, Ma J, McCauley E, Bannerman P, Pleasure D (2009) Early postnatal proteolipid promoter-expressing progenitors produce multilineage cells in vivo. J Neurosci 29:7256-7270.

Jabs R, Pivneva T, Huttmann K, Wyczynski A, Nolte C, Kettenmann H, Steinhauser C (2005) Synaptic transmission onto hippocampal glial cells with hGFAP promoter activity. J Cell Sci 118:3791-3803.

Jones MS, Barth DS (1997) Sensory-evoked high-frequency (gamma-band) oscillating potentials in somatosensory cortex of the unanesthetized rat. Brain Res 768:167-176.

Jones MV, Jonas P, Sahara Y, Westbrook GL (2001) Microscopic kinetics and energetics distinguish $\mathrm{GABA}(\mathrm{A})$ receptor agonists from antagonists. Biophys J 81:2660-2670.

Karadottir R, Hamilton NB, Bakiri Y, Attwell D (2008) Spiking and nonspiking classes of oligodendrocyte precursor glia in CNS white matter. Nat Neurosci 11:450-456.

Kollo M, Holderith NB, Nusser Z (2006) Novel subcellular distribution pattern of A-type $\mathrm{K}^{+}$channels on neuronal surface. J Neurosci 26:2684-2691.

Kukley M, Capetillo-Zarate E, Dietrich D (2007) Vesicular glutamate release from axons in white matter. Nat Neurosci 10:311-320.

Kukley M, Kiladze M, Tognatta R, Hans M, Swandulla D, Schramm J, Dietrich D (2008) Glial cells are born with synapses. FASEB J 22:2957-2969.

Lin SC, Bergles DE (2004) Synaptic signaling between GABAergic interneurons and oligodendrocyte precursor cells in the hippocampus. Nat Neurosci 7:24-32.

Lin SC, Huck JH, Roberts JD, Macklin WB, Somogyi P, Bergles DE (2005) 
Climbing fiber innervation of NG2-expressing glia in the mammalian cerebellum. Neuron 46:773-785.

LoTurco JJ, Owens DF, Heath MJ, Davis MB, Kriegstein AR (1995) GABA and glutamate depolarize cortical progenitor cells and inhibit DNA synthesis. Neuron 15:1287-1298.

Mangin JM, Kunze A, Chittajallu R, Gallo V (2008) Satellite NG2 progenitor cells share common glutamatergic inputs with associated interneurons in the mouse dentate gyrus. J Neurosci 28:7610-7623.

Matsui K, Jahr CE (2003) Ectopic release of synaptic vesicles. Neuron 40:1173-1183.

Nguyen L, Rigo JM, Rocher V, Belachew S, Malgrange B, Rogister B, Leprince P, Moonen G (2001) Neurotransmitters as early signals for central nervous system development. Cell Tissue Res 305:187-202.

Nishiyama A, Komitova M, Suzuki R, Zhu X (2009) Polydendrocytes (NG2 cells): multifunctional cells with lineage plasticity. Nat Rev Neurosci 10:9-22.

Olah S, Fule M, Komlosi G, Varga C, Baldi R, Barzo P, Tamas G (2009) Regulation of cortical microcircuits by unitary GABA-mediated volume transmission. Nature 461:1278-1281.

Pearce RA (1993) Physiological evidence for two distinct GABAA responses in rat hippocampus. Neuron 10:189-200.

Perea G, Navarrete M, Araque A (2009) Tripartite synapses: astrocytes process and control synaptic information. Trends Neurosci 32:421-431.

Rossi DJ, Hamann M (1998) Spillover-mediated transmission at inhibitory synapses promoted by high affinity alpha6 subunit GABA(A) receptors and glomerular geometry. Neuron 20:783-795.

Salami M, Itami C, Tsumoto T, Kimura F (2003) Change of conduction velocity by regional myelination yields constant latency irrespective of distance between thalamus and cortex. Proc Natl Acad Sci U S A 100:6174-6179.

Szabadics J, Tamas G, Soltesz I (2007) Different transmitter transients underlie presynaptic cell type specificity of GABAA, slow and GABAA, fast. Proc Natl Acad Sci U S A 104:14831-14836.

Szapiro G, Barbour B (2007) Multiple climbing fibers signal to molecular layer interneurons exclusively via glutamate spillover. Nat Neurosci 10:735-742.

Tanaka Y, Tozuka Y, Takata T, Shimazu N, Matsumura N, Ohta A, Hisatsune T (2009) Excitatory GABAergic activation of cortical dividing glial cells. Cereb Cortex 19:2181-2195.

Tong XP, Li XY, Zhou B, Shen W, Zhang ZJ, Xu TL, Duan S (2009) Ca(2+) signaling evoked by activation of $\mathrm{Na}(+)$ channels and $\mathrm{Na}(+) / \mathrm{Ca}(2+)$ exchangers is required for GABA-induced NG2 cell migration. J Cell Biol 186:113-128.

Velez-Fort M, Audinat E, Angulo MC (2009) Functional alpha 7-containing nicotinic receptors of NG2-expressing cells in the hippocampus. Glia 57:1104-1114.

Yang JW, Hanganu-Opatz IL, Sun JJ, Luhmann HJ (2009) Three patterns of oscillatory activity differentially synchronize developing neocortical networks in vivo. J Neurosci 29:9011-9025.

Zalc B, Fields RD (2000) Do action potentials regulate myelination? Neuroscientist 6:5-13.

Ziskin JL, Nishiyama A, Rubio M, Fukaya M, Bergles DE (2007) Vesicular release of glutamate from unmyelinated axons in white matter. Nat Neurosci 10:321-330. 